\title{
Factors contributing to poor glycaemic control in diabetic patients at Mopani District
}

\author{
NH Shilubane, M Cur \\ Lecturer, Department of Advanced Nursing Science: University of Venda
}

\section{Key words}

diabetes mellitus; glycaemia; complication; socio-economic status; support system.

\section{Correspondence address}

\section{NH Shilubane}

Lecturer, Department of Advanced Nursing Science: University of Venda Private Bag X 5050

Thohoyandou, 0950

Limpopo, South Africa

Tel : (015) 9628713

Fax: 0865402176

E-mail : hilda.shilubane@univen.ac.za

\begin{abstract}
Curationis 33 (3): 43-47
Diabetes mellitus is not only a major burden in the developed world, it is also an increasing health problem in less developed countries. Although health education could be a tool to achieve better glycaemic control, it is important to understand that health education should be adjusted to patients' literacy, cultural environment and economic status. Among other factors, lack of money has an influence on the outcome of diabetes mellitus. Thus the purpose of the study is to identify factors contributing to poor glycaemia control in diabetic patients.
\end{abstract}

Data was collected using self-report questionnaire on a convenient sample of 32 diabetic patients and unstructured, open-ended interviews on eight patients' inorder to allow them freedom of expressing themselves with regard to factors that contribute to poor glycaemic control on diabetic patients. Data was then analysed using a computer program called Statistical Package for Social Sciences. The socioeconomic factors appeared to have significant influence on glycaemic control among participants, for instance $75 \%$ of the total subjects (32) indicated that they experienced problems of accessing health care services due to lack of money. Ignorance related to where to seek support system such as educational programme, and nutrition counselling were factors that were identified to contribute to diabetic patients' poor glycaemia control.

Permission to conduct the study was obtained from the Provincial Department of Health and the managers of the institutions where the study was conducted.

Recommendations for dealing with the identified factors have been formulated. 


\section{Introduction and \\ background}

Diabetes is an increasing health problem in South Africa, where less money is available for diabetes care. It should be borne in mind that diabetes is a complex disorder that requires constant attention to diet, exercise, glucose monitoring and medication to achieve good glycaemic control. It should be taken into account that nutrition therapy and self-monitoring of glucose are the cornerstone of successful global diabetes management (Calle-Pascual 2005:364; Lewis, Heitkemper, Dirksen, O’Brien and Bucher 2007:1266). Lewis et al.(2007:1269), and Sweileh, Aker and Hamooz (2005:2) demonstrated that the control of diabetes mellitus can be better maintained if patients adhere to a prescribed treatment regimen, diet, exercise as well as compliance to appointment. Failure to adhere to the treatment regimen may not only be dangerous for patient's health but also dramatically increase the financial costs of public health services. Acute and long term complications resulting from patient's non compliance or adherence includes coronary artery disease, cerebral vascular disease, diabetic retinopathy, nephropathy, sexual dysfunction, infections and skin disorders which may be attributed to poor adherence to the regimen (programme), as it is indicated in the literature that glucose control delays the atherosclerotic process (Lewis et al. 2007: 12844; Price 2009:99; Shilubane \& Potgieter 2003:37; van de Sander, Dippenaar \& Rutten 2007:2).

Adherence rates to treatment are bad in chronic illnesses and these has been shown to be influenced by the number of medicines prescribed and the rates of daily dosages. Secondly, drug regimen for patients with diabetes is becoming increasingly complex, and adherence may be even more challenging (Bezie, Molina, Hernandez, Batista, Niang \& Huet 2006:611).

High fasting blood glucose levels was found to be caused by inadequate knowledge about diabetes as patients who receive no information from a nurse had a fasting blood glucose of $14.5 \%$ compared to fasting blood glucose of less than $8 \mathrm{mmol} / \mathrm{l}$ for those who received information (van de Sander et al.2007:7) .

\section{Problem statement}

It is evident from literature and statistics at one of the public hospital that the incidence of diabetes is increasing and that although there is evidence that the complications of diabetes can be prevented, there are still patients who fail to maintain their blood glucose at a normal level. The current statistics for diabetic patients at one of the public hospital moved from $6.9 \%$ in 2006 to $49.3 \%$ in 2008 . In this study the researcher attempts to identify factors in diabetic patients that contribute to poor glycaemia control.

\section{Research objectives}

The following research objectives were formulated to guide the researcher:

- $\quad$ identify factors that contribute to poor glycaemic control in diabetic patients.

- $\quad$ make recommendations for health professionals addressing the identified factors.

\section{Research design and setting}

A Concurrent Triangulation Strategy was used to collect data. It is a strategy where the researcher uses two different methods in an attempt to confirm; cross validates, or integrates the results of the two methods during the interpretation stage. In this strategy, quantitative and qualitative data collection is conducted simultaneously (Creswell 2003: 217).

The different methodological perspectives complement each other and thus it is conceived as the complementary compensation of the weakness and blind spots of each single method (Flick 2009:26). Quantitative data was collected through the questionnaire to obtain information about the factors contributing to poor glycaemia control. Open-ended interviews were used to obtain in-depth information of those factors contributing to poor glycaemia control.

The study was conducted at a public hospital, which falls under the Lowveld region, Mopani District in the Limpopo Province (RSA). The hospital has bed occupancy of 253, caters for 20 clinics and caters mostly black clients.

\section{Population and sampling procedures}

The study population consisted of all the diabetic patients in the Mopani District that falls under the Lowveld region in the Limpopo Province, South Africa. The subjects were diabetic patients admitted to the hospital because of the disease. For quantitative design a convenient sample of 32 diabetic patients who were admitted in the wards was chosen. Subjects had to meet the following specific criteria: willing to participate, 21 years or older, literate and illiterate, mentally sound to give consent, of either gender or any race. For qualitative design, purposive sampling was used to select the participants who represented this population, and data saturation (Berg 2009: 50) was reached after interviewing eight (8) respondents.

\section{Method of data collection}

Data was collected using questionnaire and interviews. For quantitative design, a self-report questionnaire was used to collect data about the subjects' biographic data, financial status, support systems, educational as well as nutrition counselling. The researcher personally delivered the questionnaire to diabetic patients in adult male and female general wards. The data was collected over the period of three months.

Questionnaire was in both English and Xitsonga to enable those who did not understand English to answer in Xitsonga since the majority of the residents speak this language.

Subjects who could not read were assisted by the researcher who remained with them, read the questions for them and then indicated their responses on the questionnaire.

A three Likert scale allowed the participants to indicate whether they agree, disagree or unsure with factors contributing to poor glycaemic control. Statements such as "Lack of money interferes with diabetes control, Patient stays alone at home, Patient attended programmes dealing with diabetic issues, Patient attended nutrition counselling were included on the questionnaire.

In collecting a qualitative data, unstruc- 
tured, open-ended interviews were conducted on eight patients after completion of the questionnaire. The interview was aimed at giving the participants opportunity to express their views on factors contributing to poor glycaemia control (Creswell 2003:210). The broad question was "what are the challenges in managing your disease"

The researcher interviewed the participants in Xitsonga in order for the participants to present the data without distorting the information. Translations were done from Xitsonga to English by a language expert.

\section{Data analysis}

Data analysis was done based on the questionnaires that related to factors contributing to poor glycaemic control using Statistical Package for Social Sciences. For the closed-ended questions descriptive statistics were used.

The open-ended questions were analyzed by the researcher through content analysis and Tesch's stages of data analyses. All the transcriptions were read carefully and some ideas were jotted down as they came to mind. The researcher went through the interviews, and wrote thoughts in the margin. List of all topics were made and similar ones were clustered together.

\section{Reliability and validity}

Reliability according to Schneider et al (2004:448) refers to consistency of measuring instrument. If there is more than one way of interpreting what the researcher wants, it means that the instrument is ambiguous and thus unreliable. In this study reliability was ensured by having the researcher being the only person to conduct the interview and to administer the questionnaire, exhibiting similar personal attributes to all respondents, for example, support, ensuring privacy, and confidentiality.

The validity of an instrument is the degree to which an instrument measures what it is intended to measure (Schneider et al. 2004:451). Content validity refers to the extent to which an instrument represents the factors under study. Content validity was ensured by consistency in administering the questionnaire. Questionnaire was distributed to subjects by the researcher personally.

The questions were formulated in simple language for clarity and ease of understanding. Clear instructions were given to the subjects and the researcher completed the questionnaire for those subjects who could not read. Piloting the questionnaire and the interview guide was also done to five patients at the public hospital.

\section{Ethical considerations}

Permission was obtained from the Research committee of the Department of Health (DoH) of Limpopo Province and assistant Director of a public hospital. This was in the form of writing. In the wards verbal permission was obtained from the matron in charge. Respondents were requested to sign a consent form before participating in the study and it was separate from the questionnaire to maintain anonymity. Potential participants were informed that they may withdraw their participation at any time, and that anonymity and confidentiality of the data collected during the study would be maintained. To ensure anonymity, respondents were not expected to write their names on the questionnaire.

For interviews consent was obtained from interviewees. They were informed about the recordings that will take place during the interviews. Interviewees were not expected to mention their names during the interviews and were assured that their names would not be used during publication of the findings.

\section{Presentation of findings and discussion}

A brief description of the demographic data of the participants is done. A discussion of factors that contribute to poor glycaemic control in diabetic patients follows the demographic data.

\section{Background information of participants}

The study participants comprised of African patients aged 21-60 years. They were 12 male and 20 female living in Limpopo province, South Africa. Of the 32 patients, 24 were literate and 8 illiterate (they could not read and write).

Table 1 present the quantitative findings and the following questions were asked:

- $\quad$ Lack of money interferes with diabetes control

- $\quad$ Patient stay alone at home

- $\quad$ Patient attends programmes dealing with diabetic issues

- $\quad$ Patient attended nutrition counselling

\section{Factors contributing to poor glycaemia control in diabetic patients}

\section{Lack of money interferes with diabetes control}

From table 1 it is clear that (75\%) of patients agreed that lack of money does interfere with the control of blood glucose as patients cannot afford to buy the necessary food and visit the health institutions for check-ups and collection of treatment, thereby leading to elevated blood glucose due to non adherence to treatment and advises. According to Baumann, Chang and Hoebe (2002:191) the morbidity from diabetes is more severe in low income groups, and less than half of adults with type II diabetes in their study achieved a blood glucose level of less than $7 \mathrm{mmol} / \mathrm{L}$. 
This indicates the negative effects of lack of control of diabetes, which may be due to lack of money.

Expense was also reported as causing frustration, and Peyrot (2008:10) demonstrated a significant financial burden experienced by diabetic patients due to their diabetes

If diabetics want to sweeten their tea they have to use sweeteners which can be purchased from pharmacy. If they have elevated blood pressure they should use the special salt recommended for them. All these cost money and are expensive compared to the normal cane sugar and iodised salt used daily. This is supported by the study done by Shilubane \& Potgieter (2003:82 and 2007:63) who demonstrated that some patients justified their adherence to treatment on basis of economic factors.

\section{"What are the challenges in manag- ing your disease?"}

This is the open question which was asked to eight (8) respondents. The question followed immediately after questionnaire completion. The following were their responses: "The biggest challenge is lack of money, I am not employed" Several probes were then used such as in which way can lack of money interferes with diabetes control? The responses were: "Everything needs money, it is difficult for me to follow the advices that the nurses give me; I must eat special diet, use special sugar and visit the clinic for check-up and treatment, and all this become impossible without money; I am unemployment, and the situation becomes worse and I don't know where to start”.

\section{Support system}

\section{- $\quad$ Patient stays alone at home}

In response to this question $(9.4 \%)$ patients reported that they stay alone, (65.6\%) stay with their spouse, (15.6\%) with their parents and (9.4\%) with their relatives. This indicates that the majority of diabetic patients in the sample don't stay alone and therefore have a support system available. Danne, Lange \&Ziegler (2008:23), Paddison (2010:29) and Peyrot (2008:11) demonstrated that patient's type of support may influence self management behaviour. Individuals are more likely to adhere to their diabetic health regimen if the quality of their interaction and rela- tionship with their health providers is good and if the individuals have good social support. Patients whose families are supportive follow the recommended diet or a diabetic regimen.

Toljamo and Hentinen (2001:626) support Danne et al. (2008:23) who demonstrated that peer support is important for patients with diabetes mellitus as it promotes adherence to self-care, and that people with type 2 diabetes who have no personal support system, tend to have earlier and more serious complications leading to shorter lives. They further indicated that emotional support might be a motivating factor in improving adherence to health recommendations. Keller also maintains that the diabetic patient's adjustment to the disorder depends largely on family support, and that negative patterns of interaction within the family affect the adherence to the diabetic regimen.

With whom do you stay at home? Was the probing question used.

Two respondents said:” I stay alone, things are expensive and staying with someone means financial problems". Six of the eight respondents indicated that they stay with family members, and that it is important to have someone at home because they remind them to take their treatment, I quote "I stay with my spouse and children; I stay with my sister and her children look after me when I am sick". The findings indicate that the participants have got individuals to support them during management of their disease and when they are sick.

\section{- $\quad$ Patient attends programmes dealing with diabetic issues}

Findings of this study (59.4\%) revealed that they had never attended organised programmes and attending such programs can assist them in gaining information and support from the relevant professionals. According to findings by Danne, Lange and Ziegler (2008:23), Paddison (2010:29) and Peyrot (2008:11), adherence to the diabetic regimen is influenced by the type of support system the patient has. A support system is an organised group of individuals that encourages or assists. Attending programmes may avail the patients opportunity to interact with other individuals, and thus assist them to cope with the disease follow- ing advises that they may get. Social contact with local interest groups help patients share information on regular home monitoring of blood and urine glucose levels, weight control, dietary restrictions, regular exercise, foot care, and eye care. This is affirmed by Kyngas and Rissanen (2001:771) who indicate that the predictor of good compliance includes support from nurses, physicians, parents and friends. Rasmussen, Wellard \& Nankervis (2002:629) state that if patients are encouraged to actively participate in decisions, they ultimately achieve higher levels of compliance.

Have you ever attended any programme that addresses diabetic issues? This was followed by how many and which ones have you attended?

Seven of the eight respondents indicated that they never attended any programme. One said: "I attended two programmes, one was a diabetic awareness day at the stadium and the other one was a gathering for diabetic patients".

\section{- $\quad$ Patient attended nutrition counselling}

Almost half of the patients 15 (46.9\%) of 32 participants never went for nutrition counselling and therefore the correct diet for diabetic patients. It is a known fact that diabetic patients should consult a dietician for advice on their diet following diagnosis. It is alarming that so many of the subjects did not have nutrition counselling, as the correct diet is a very important part of the management of diabetes. This is supported by Savoca and Miller (2001:225) who indicate that most people with diabetes mellitus fail to adhere to a healthy diet which might be due to failure to attend nutrition counselling offered by a dietician.

Further more van de Sande et al (2007:10) demonstrated that nutrition therapy for black patients is unsuccessful when the diet prescription does not relate to the patient's cultural environment and economic situation and is presented in ways that are difficult for low literacy patients to understand and implement.

\section{How much nutrition counselling have you attended?}

All respondents indicated that they 
attended nutrition counselling. Their responses were: "I received an advice about nutrition once from nurses, Every time I visit my doctor she reminds me about my diet and its importance, the nurses referred me to the dietician after my diagnoses and once a year I consult to get new information on the diet, I went to the dietician once because I have to pay and I do not go anymore due to lack of money. Thus all the interviewee received some advices regarding their diet.

\section{Limitations of the study}

The major limitation is that only adult patients in the general wards were included in the study, yet there are adolescent diabetic patients.

\section{Recommendations}

The following recommendations are proposed:

- $\quad$ Social workers to arrange social grants for non working patients, to enable them to access health facilities and buy the necessary food.

- $\quad$ Patients' family members should be encouraged to support the patients and made aware of the supportive role they play by supervising patients on their diet, taking of medication, exercise and regular visits to the clinic for glucose monitoring and collection of treatment.

- $\quad$ Patients should receive proper counselling on nutrition from nurses. If available, nurses should refer patients to a dietician. It should be stressed that diabetes requires lifelong adherence to the treatment regimen to control the disease, thereby preventing complications

- $\quad$ Patients must be referred for psychological counselling by a psychologist or psychiatric nurse if necessary.

\section{References}

BAUMANN, LC; CHANG M \& HOEBEKE, R 2002: Clinical outcomes for low-income adults with hypertension and diabetes. Nursing research $.51(3)$.

BERG, BL 2009: Qualitative research methods for the social sciences. $7^{\text {th }}$ edition. New York: Allyn \& Bacon.

BEZIE,Y;MOLINA,M;HERNANDEZ, N; BATISTA, R; NIANG S \& HUET, D 2006: Therapeutic compliance: a prospective analysis of various factors involved in the adherence rate in type II diabetes. 611-616.

CALLE-PASCUAL, AL 2005: Diabetes nutrition and complications trial: adherence to the ADA nutritional recommendations, targets of metabolic control, and onset of diabetes complications. A 7-year, prospective, population-based, observational multicenter study. Journal of Diabetes and its complications, (20): 361-366.

CRESWELL, JW 2003: Research Design: Qualitative, Quantitative, and Mixed Methods Approaches. $2^{\text {nd }}$ edition. Thousand Oaks: SAGE Publications.

DANNE, T; LANGE, K \& ZIEGLER,C 2008: Peer support and positive results in Germany- repeating success at my camp D. Diabetes voice. (53):23-24.

FLICK, U 2009: An introduction to qualitative research. $4^{\text {th }}$ edition. London: SAGE Publications.

KYNGAS, H \& RISSANEN, M 2001: Support as a crucial predictor of good compliance of adolescents with a chronic disease. Journal of clinical nursing, (10):767-774.

LEWIS, SM; HEITKEMPER, MM; DIRKSEN, SR; O'BRIEN, PG \& BUCHER, L 2007: Medical-Surgical Nursing: Assessment and management of clinical problems. $7^{\text {th }}$ Edition. Mosby: Elsevier.

PEYROT, M 2008: How is diabetes perceived? The results of the DAWN youth survey. Diabetes voice, 53(2008): 9-13.

PRICE, D 2006: Sexual problems in diabetes. Medicine, 34(3) 99-100.

RASMUSSEN, B; WELLARD, S \& NANKERVIS, A 2002: Consumer issues in navigating health.

SAVOCA, M \& MILLER, C 2001. Food selection and eating patterns: themes found among people with type 2 Diabetes Mellitus. Journal of Nutrition Education, 33(4):224-338

SHILUBANE, HS 2003: Knowledge of patients and family members regarding diabetes mellitus and its treatment. MA Dissertation. Pretoria: UNISA.

\section{SHILUBANE, HS \& POTGIETER, E} 2007: Patients' and family members' knowledge and views regarding diabetes mellitus and its treatment. Curationis, 30(2):56-65, June.

SCHNEIDER, Z; ELLIOT,D; WOOD, GL \& HABER, J 2004: Nursing Research: Methods, Critical Appraisal, and Utilization. $2^{\text {nd }}$ edition. Philadelphia: Mosby, Inc.

SWEILEH,W;AKER, O \& HAMOOZ, $S$ 2005. Rate of compliance among patients with Diabetes mellitus and Hypertension. An-Najah Univ.J.Res. (N.Sc.), (19):1-11.

TOLJAMO,M \& HENTINEN,M 2001: Adherence to self-care and social support. Journal of Clinical Nursing, (10):618-627.

VAN DE SANDE, M; DIPPENAAR, H \& HUTTEN, GEHM 2007: The relationship between patient education and glycaemic control in a South African township,1-12. 